\title{
Practicing transformative planning: the territory-landscape plan as a catalyst for change
}

\author{
Louis Albrechts ${ }^{1}$, Angela Barbanente ${ }^{2^{*}}$ (1) and Valeria Monno ${ }^{2}$
}

\begin{abstract}
This paper advocates the need for transformative planning practices to cope with contemporary crises of climate change and intensifying economic inequality that regions, city-regions, and cities are increasingly confronted with. In-depth examination of planning processes is useful to grasp some crucial promises and problems of transformative planning and open up new possibilities for practice. Accordingly, the paper includes an investigation into the Territory-Landscape plan-making process developed in the Apulia region, Italy. This explicitly and intentionally aimed at promoting a radical discontinuity in regional planning culture and practice by changing the well-established relationship between territory-landscape protection and spatial planning. The process revealed that 'landscape' could function as a constructive picklock for proposing an alternative to the development-as-growth model firmly entrenched in the region, and envisioning desirable futures focused on the concept of 'local self-sustainable development'. This implies subverting the hegemony of the 'economic' that has reduced dwellers to consumers, and the territory to a mere physical support for any kind of land transformation and urban development which exclude dwellers participation. Using the lens of transformative theory and building on an interpretive research approach that included also direct experience, the paper provides insights on changes in vision and concepts, discourses and practices, approach and instruments experienced in such a planning process. In conclusion, it reflects on lessons learned, and highlights some difficulties and contradictions with which the way towards transformative planning is paved for researchers engaged in turning their ideas into significant achievements in the real world.
\end{abstract}

Keywords: Transformative planning practices, Territory-landscape, Situated planning processes, Self-sustainable local development, Planning vision and concepts

\section{Claiming change: planning ambitions and contextual conditions}

Our globalised and increasingly urbanised society faces the combined contemporary crises of climate change and intensifying socio-economic inequality and global economic disruption (Pelling et al. 2011). While some believe in the strength of creative capitalism and thein their view-huge improvements in quality of life it can provide (Gates 2008), others are convinced that the current challenges are central and structural, and hence

\footnotetext{
*Correspondence: angela.barbanente@poliba.it

2 Politecnico di Bari, Bari, Italy

Full list of author information is available at the end of the article
}

cannot be tackled by means of traditional approaches (Hames 2007), by "just more market" (Hamilton 2004; Sachs and Esteva 2003), by extrapolating from the past and the present, by simply relying on economic growth (Hamilton 2004; Mishan 1967). This paper argues that society as a whole has to accept that it lives in a world in which much of what it does and how it does it simply cannot continue (Hames 2007, p 278). There is ample evidence that the problems and challenges that regions, city-regions, and cities are confronted with cannot be tackled and managed adequately either on the basis of the neoconservative perspective or on the basis of the intellectual, technical-legal apparatus and mindset of traditional planning. This implies that only the proactive 
response (Ackoff 1981) seems appropriate, as it calls for the transformative practices that are needed to cope with the continuing and unabated pace of change driven by (structural) problems and challenges.

Transformative practices not only refuse to accept that the current way of doing things is necessarily the best way. Transformative practices must be imagined as differing radically and structurally from the present reality. They focus on new concepts and new ways of thinking that change the way resources are used, (re)distributed, and allocated, and the way the regulatory powers are exercised (Albrechts 2010, p 1117). As a concrete sociohistorical practice aimed at socially producing a radical change, transformative planning-within an intrinsically changing, fluxing, and transforming social and physical reality (see Chia 1999, p 210) - is called upon to recognise the forces of change and to look for visions, means and instruments to produce alternatives.

With references to radical change, transformative planning has been conceptualized in different ways. A number of strong manifestos for change have been drawn up-for reconsidering the absolute faith in economic growth (Mishan 1967; Hamilton 2004), for living interculturally (Landry 2000; Sandercock 1998), for creating a more sustainable society (Sachs and Esteva 2003), for social mobilization (Friedmann 1987), for an urban political ecology (Heynen et al. 2005), for recapturing democracy (Purcell 2009) and for a more radical planning (Albrechts 2013, 2015). These manifestos rise some crucial general questions when confronted with the actual rationalities involved in diverse systems and processes of planning practice, such as: in which direction should change move, and which forces of change need to be mobilised? what substantive contents should nurture the planning process in different action contexts? and what planning instruments are more suitable to favour transformative practices? Conceptualisations of radical change depend on context. Planners have to recognize the situated nature of processes, knowledge and values which guide both urban and regional planning approaches and transformations at the local level.

A focus on practices could be helpful to grasp such crucial aspects. Accordingly, this paper focuses on the territorial-landscape plan (TLP) for the Apulia region, Southern Italy, which was approved in 2015 after 7 years after its outset. This planning process explicitly and intentionally aimed at promoting a radical discontinuity in the regional planning culture and practice by changing the established relationship between territory-landscape protection and spatial planning.

The TLP is a spatial plan that applies to the whole regional territory. It was part of the cultural and political change occurring in Apulia and related efforts to support an alternative vision of regional spatial development. Its concepts, content and process challenged the "urbanism tradition" (CEC 1997) characterising the regional planning system; they also broke with the Italian first generation of regional landscape plans in compliance with the national law n. 431/1985. Finally the TLP differed significantly from the late 1990s-early 2000s regional spatial plans, which were generally centred on principles that are difficult to reconcile such as sustainability, competitiveness, and territorial cohesion (Fabbro 2003).

In what follows we will reflect on the TL planning experience, with the aim to highlight its transformative ingredients and potentials. This paper is biased and somehow unbalanced to the extent that it is written from an insider's perspective as one author was in charge of the plan. She is an academic who, from 2005 to 2015, was appointed as deputy president of the Apulia regional government with responsibility for spatial planning, landscape and cultural heritage. In our interpretive research approach (Yanow 2000), this unconventional participation was an opportunity to deepen our analysis of the TL planning experience and grasp its situated and contextdependent aspects. Her immediate involvement made it a real-life account of planning-in-action. It offered a more intimate view of the decision-making process than could be obtained from any other perspective (for a comparable approach see Meyerson and Banfield 1955; Krumholz and Forester 1990). Thus, our analysis is based not only on the critical revision of official documents and multimedia information, but also on first-hand materials such as minutes of political and technical committees and accounts of formal and informal meetings during the long and turbulent process of drawing up and approving the plan.

The paper reflects on the TL planning process. It describes the key cultural and political contextual conditions that contributed to trigger the TLP as a transformative planning experience. Then it discusses its transformative content focusing on changing vision and concepts, discourses and practices, and planning approach and instruments. Finally it points out what can be learned from and about transformative planning from this experience.

\section{A framework for grasping the transformative in TLP}

Several powerful and catching concepts in planning are very slippery. They can mean different things to different people and be used in several different ways and be contested. Transformative practices is one of them.

The transformative agenda is a modern term for structural change that has been discussed by many in the past (see Ozbekhan 1969; Schön 1971; Etzioni 1971) in the 
context of planning theory. From our point of view, transformative practices focus on the structural problems in society; they construct images/visions of a preferred outcome and how to implement them (see Friedmann 1987). Transformative implies refusing to accept that the current way of doing things is necessarily the best and therefore abandoning the usual boundaries of 'reasonableness' (see de Bono 1992). It claims for generating discontinuity and changing concepts, structures and ideas that only persist because of the process of continuity. Transformative is about discontinuity and a conception of 'futures' that transcends mere feasibility and that results from judgments and choices formed, in the first place, with reference to the idea of 'desirability', to the idea of 'betterment' and to the practice of the good society (Friedmann 1982). Futures have to be imagined as differing radically and structurally from the present reality. Thus, transformative planning becomes the activity whereby (within certain boundaries) the purpose of changing differs from the established or traditional way of thinking, in which there is no choice and we are not even aware of other possibilities.

From a radical perspective, the starting point of transformative practices is always a concrete problem. "Transformative theory" focuses on the structural problems of capitalist society viewed in a global context and provides a critical interpretation of existing reality. Such a theory cannot be arbitrarily invented. It must grow out from and be informed by long periods of sustained oppositional practice. Based on experience, it combines an amalgam of analysis, social vision, and hard strategic thinking with the intent to shape ongoing political practice, even as it continuously absorbs new learning (Friedmann 1987, pp 389-390).

From a radical perspective transformative practices involve constructing 'desired' answers to the structural problems of our society through citizens mobilisation. They entail developing visions through social production processes which are not merely temporal extensions of the here and now but symbolize more just and solidaristic socio-spatial assets as a result of constant confrontation on the places in which we want to live in, or think we should live in. Envisioning is a collective process linked to values, to choices, and therefore is far from neutral.

Primary objective of transformative planning is the recovery of political community and, with it, an active public life. A process of recovery involves both "self-production of life" and "collective self- reliance" (Friedmann 1987, p 386). As such, transformative (radical) planning stands in necessary opposition to the established powers. Three kinds of politics are relevant: politics of empowerment, politics of redistribution, and politics of place (Friedmann 1987, pp 407-408). While politics of redistribution pertains to the national level, politics of empowerment, which takes place over claims staked out around the major bases of social power, and politics of place, which sets out to defend people's life spaces against the rapaciousness of capital and bureaucratic fiat, are up to the regional and local levels.

Politics of empowerment and politics of place can strengthen each other in co-production processes at the regional and local levels. In transformative planning, these processes are interpreted as mobilizing practices of collective political organization and action. Drawing on awareness of causes of inequality and path dependency, they involve communities in co-producing practices that can be transformative to the extent that they are able to enlarge the imagination of possible alternative futures, provoke a shift towards sociospatial justice, and ground their legitimacy in a future to be brought about, that is an idea to realize (Albrechts et al. 2019).

\section{A region in search of a different way of dealing with structural 'underdevelopment' problems}

Apulia is a peninsula of $19.347 \mathrm{~km}^{2}$ and approximately $900 \mathrm{~km}$ of coastline, with almost 4.1 million inhabitants and 258 municipalities ranging from 320.000 to 150 inhabitants. It is located in Southern Italy, the so-called Mezzogiorno. This is an area characterized by a longterm economic gap from Central to Northern regions: in 2016 the unemployment rate $(19.4 \%)$ was well above the national average (11.7\%), and the per capita GDP was considerably lower than the national average $(65.1 \%){ }^{1}$

In this region as in the whole Mezzogiorno, modernist development policies implemented after the World War II have always been unsuccessful. Such a failure is at the base of the widespread narrative depicting the Mezzogiorno as an 'underdeveloped' community. However, Apulia has always been a more complex environment that could not be easily stigmatised as 'underdeveloped'. At the end of the 1990s-beginning of 2000s, such an inconsistency between the dominant narrative and the contextual specifics gave rise to a critical thinking emphasising the failure of exogenous development policies as a result of political patronage and dominant economic interests. The emergence of such critical thinking determined a myriad of macro, and above all, micro political changes. These in turn stimulated the construction of a different narrative on the Apulia development, including numerous social, cultural and political ideas and practices providing alternatives to the post-World War II development-as-growth model. Accordingly, a new regional storytelling emerged, which was capable of

\footnotetext{
${ }^{1}$ Eurostat (2017) http://ec.europa.eu/eurostat/data/database.
} 
overcoming socio-institutional barriers and changing the established collective imaginary. It was centred on the criticism of a world ruled by the "business fundamentalism" and an "obsessive competitive pressure", which has condemned the South, in its pursuit of progress imposed by the capitalist system, to become an incomplete, imperfect, and not-yet North (Cassano 2012, pp xvii-xviii). It explained the difference between the Mediterranean and Northern thinking and showed the Mediterranean differential, autonomous identity to be recovered and rediscovered in terms of an alternative world (Cassano 2012). The Mediterranean alternative thinking catalysed several different and yet divided components of a nascent, fragmented civil society including catholic movements, the radical left, local environmentalism, and other NGOs. As all over the world, in Apulia too as a result of the crisis of representative democracy, a lively local civil society was slowly coming to light. Although underrepresented, this civil society developed, and its ideas spread throughout the region inspiring the old as well as new generations. It promoted another democratic political system: one led by engaged citizens/society acting for the common good. However, it lacked leadership and a clear and catalysing alternative development model (Cassano 2004). Some NGOs and other civil society organisations established close relationships with a group of intellectuals, academics and professionals from different fields, including urban and regional planning. They called for a self-directed line of thought as a base for enacting a new, endogenous development path.

In such a vital cultural environment, Nichi Vendola, a politician of the so called "radical left" (March 2011), surprisingly won the primary election of the centre-left coalition in 2005, and in the same year was elected president of the regional government. This election was the first one giving birth to a government leaded by a radical left party both in Italy and in Apulia, a region which in the past had been uninterruptedly governed by centre and right-wing political coalitions.

Such a victory was supported by a political program proposing a different vision of the development potentialities of the region, drawn on ideas of political, cultural and entrepreneurial change. All this contributed to turn discontent into new hope. The president was re-elected in March 2010, and thus governed until 2015.

The regional government proposed a form of ruling merging in a unique manner leadership and participatory rituals (Romano 2005). It expressed a viable alternative to the centre-right managerial, technocratic, efficiency-oriented one characterising the previous 2000-2005 government (Gelli 2006). Some regional government members had the active backing of the political, social and cultural movements, which had sprung up throughout Apulia out of already existing and active civil society groups working on local political issues (Romano 2005).

The new regional government proposed a change from both the historical condition of marginality of Apulia to a new identity based on its Mediterranean belonging, and the deeply rooted practices of political patronage and economic lobbyism to grassroots democracy (Duran 2015, pp 251-252). The political vision distanced itself from the post-World War II development-as-growth model based on the emulation of 'more (economically) developed' areas. This model had been supported by a land use planning system essentially centred on municipal land use plans mainly concerned with the management of future (abundant) options for urban expansion. In a region depicted as 'underdeveloped', local governments and communities had usually regarded positively any development, hoping to gain local economic and employment benefits. This hope had made them overlook the degradation and destruction of environmental and cultural heritage, as well as the erasure of local knowledge, experience and skills, provoked by such development.

In opposition to the post-World War II development model, the regional government envisioned a development perspective focused on the enhancement of social capital, especially youth, and culture and environment considered as common goods (Damiani 2011). ${ }^{2}$ This opened the opportunity for planning to find a new role in regional development policies, centred on the protection and enhancement of the territory as the historical product of long-lasting cultural processes in coevolutive relationship with the natural environment. This was a demanding challenge, which required a new planning ethic and the design and implementation of different planning instruments. The TL planning process which started in 2007 was one of them.

\section{The TLP as a catalyst for change}

Against the backdrop discussed in the previous sections, the TLP was intended as a support to change the culture and practices of territorial transformation, and start the construction of a new history in the collective interpretation and production of the regional territory.

The TLP is a statutory spatial planning instrument legally required by the national Cultural Heritage and Landscape Code (hereafter Code), approved in its final form in 2008. However, in discontinuity with the dominant planning approach both at the local and regional

\footnotetext{
${ }^{2}$ See the "Programmatic Declarations" of the president to the regional council on the initiation of "a new development cycle based on the strengthening of tangible and intangible resources, set up by women, men, youth, and cultural and environmental heritage of the territory".

http://old.regione.puglia.it/web/files/presidente/dichiarazioniprogrammatic he.pdf.
} 
level, the TLP adopted a strategic approach. It can be defined a strategic plan embedded in a statutory setting. In sum, it combined a long-term vision, a selective range of objectives and issues, an open, proactive approach to plan-making and implementation, with statutory legal certainty and clear rules for the transformation of protected areas.

Key actors of the TL planning process were academic researchers in different positions. They constituted the planning team. The TLP preparation offered them the opportunity not only to experience their knowledge or understand the realities of planning practice but, more importantly, to turn their critical analyses of usual planning practices into proposals for change. The deputy president of the Apulia regional government, who promoted the TLP, together with a small group of planners and some environmentalist associations, had been questioning the dominant spatial planning practices, and therefore the positions of most professionals who tended to side with powerful lobby groups, such as the construction industry. The scientific coordination of the plan was given to Alberto Magnaghi, an activist planner (Sager 2016), university academic and founder of the socalled 'territorialist school.' The preparation of the plan was entrusted to a group of 15 young experts in different fields, many of which PhDs, who later became an inhouse planning team hinged on the organization of the regional planning department. ${ }^{3}$

\section{Towards a new development vision}

The TLP vision was based on the concept of "self-sustainable local development" (Magnaghi 2005). This implies subverting the hegemony of the 'economic' that has reduced dwellers to consumers, and the territory to a mere physical support for any kind of land transformation and urban development which exclude dwellers participation. The ultimate goal of the perspective of self-sustainable local development is to reconnect dwellers and producers in the protection and enhancement of territory values as foundations for an alternative development that finds in the reproductive rules of local resources its self-generating capacity and durability (Magnaghi 2005, p 69). As such, self-sustainable local development calls for a continuous learning process of local communities, aimed at increasing their "place consciousness", that is their ability to recognise and appreciate meanings and qualities of places, and shape and take care of their living environment. The concept of landscape was essential to this purpose.

\footnotetext{
${ }^{3}$ In addition to this planning team, academics from diverse disciplines were involved in the scientific committee, and two research companies provided support in some phases of the planning process: the Istituto per la Ricerca Sociale (IRS), Milan, and IUAV Studi and Progetti, Venice.
}

Landscape has an intrinsically ambivalent nature. It denotes the external world mediated through subjective human experience (Cosgrove 1984). The term landscape recalls the aesthetic values of the Italian beauty, and therefore is deeply engrained in the Italian culture. The quality of landscape as an aspect of local identity belongs to the collective imaginary of Italian people, albeit in complex forms that cannot be traced back to an idealized landscape as symbolic of national identity (Agnew 2011). Apulian landscapes are strictly linked to human work. Owing to the flat or gently hilly morphology of the region, its landscapes have been largely 'built by hand' and mirror physical and social change through historical and contextual experience. On the other hand, the European Landscape Convention (Council of Europe 2000) provided a wider framework to shift the focus of landscape conception from private interests to the common good (Pedroli et al. 2013; Settis 2013). All of these factors made the concept of landscape become a powerful picklock for changing spatial planning practices through the TLP.

Stories play a crucial role in transformative planning because they can be powerful agents or aids in the service of change, as shapers of imagination of new alternatives (Sandercock 2003, p 18). The planning team played an important role in changing the well-established storytelling through the construction of a new narrative. This was selective and purposeful, i.e. partisan, based on choices that involve values, and contestable. It was not only persuasive but also constitutive (Throgmorton 2003, pp 128-130). The new narrative included the representation of the criticalities left by the metropolisation of the territory and the impacts that this generated on the quality of places, in terms of dissemination of urbanization, fragmentation of urban living, degradation of public space, standardisation of landscapes (Magnaghi 2005; Nogué and Wilbrand 2017). The new narrative provided future-oriented figures/forms/images that unsettled the existing social imaginary and the real and rational works produced by it.

\section{Constructing new narratives and practices}

The new narrative was constructed interactively through a process that the planning team defined the Social Production of the plan. Such process started at the very beginning of the plan drafting, and involved citizens, associations, stakeholders, and local authorities, on the one hand, in increasing collective awareness of criticalities in usual practices of land use transformation, on the other hand, in generating a "collective becoming" (Metzger 2013): becoming attached to a place, seeing oneself as part of and also as caring for place. This was anything but easy in a region of about 20 thousand 
square kilometres and 4 million inhabitants. It required the use of several devices, each of them more or less suitable for listening, involving, activating, and empowering different public and private organizations, institutions, associations, social groups, and individual inhabitants.

In addition to hundreds of informal meetings, thirteen formal conferences were held in cities and villages throughout the region. In the initial stage of the processes, images and photographs were used to emphasise the negative social, economic and environmental consequences produced by a development model based on the absolute faith in economic growth: marginal ghetto neighbourhoods, low quality buildings and infrastructures, standardised settlement in the peri-urban areas, severe anthropic pressures on coastal eco-systems obstructing the public use of beaches. The negative situations were connected to the future visions, projects and actions. An Internet site was constructed to provide continuously information on plan-making progress and an on-line Landscape Observatory was created to facilitate interaction between citizens and the planning team. Anyone interested in making their voices heard could point out on a GIS map what they perceived as landscape values to be protected or damages inflicted to them, and as best practices to be promoted and worst practices to be prevented. A prize was launched for the promotion of best practices in landscape protection and improvement.

The Social Production fed not only on discourses but also on practices. It was also intended as a way to discover a number of bottom-up initiatives to be strengthened and developed, or to promote and initiate new ones. As such, the Social Production acted as a catalyst for mobilizing latent wills and energies of individuals and groups, and actively involving them in the plan-making process. It brought to light counter-hegemonic groups that had been active in defending local territories-landscapes against development-as-growth land use planning. It disclosed situated practices promoted by a lively local civil society acting for the common good. These practices were socially innovative initiatives focusing on place qualities and liveability, experiments of alternative modes of place management, opposing the ideas of territory and landscape underlying business-as-usual planning practices. The Social Production activated a tight cooperation between the TL planning team, government and non-government planners, and civil society groups, who co-produced transformative planning practices that were defined Experimental Integrated Projects. ${ }^{4}$

\footnotetext{
${ }^{4}$ About fifty local authorities and several active civil society groups carried out thirteen projects during the plan-making processes: https://www.paesa ggiopuglia.it/osservatorio-del-paesaggio/progetti-sperimentali.html.
}

The TL planning team used such projects purposively as examples to show possible alternative modes of description, interpretation and transformation of local territories-landscapes. The regional government gave them relief, prominence and funding. In areas lacking of public or private proactive actors new projects were promoted. The former were used as concrete practices from which the latter could draw inspiration. Some projects mainly focused on creating and enhancing social and cultural values, such as eco-museums and community maps. In other ones the improvement of physical environment prevailed. These included projects for river rehabilitation, for the re-use of old sheep tracks, for recovery, conservation and improve of agrobiodiversity in marginalised rural areas, a slow mobility network and a guesthouse for a protected area, redevelopment projects of natural chasms and canals falling in an endoric basin for tourism use, environmental regeneration of peripheral urban areas, the recovery of degraded areas of abandoned quarries, and the enhancement of cultural and environmental values in internal rural areas. They contributed to the transformative agenda by pointing out concrete ways to tackle long-lasting structural problems exacerbated by the post-WWII development model, such as migration of young people, abandonment of agricultural land, environmental degradation in urban and coastal areas, increase in inter- and infra-regional disparities. For example, they suggested the vision of a new alliance between city and countryside, which became a territorial project at the regional scale that was defined the "citycountryside pact". This aimed at halting the long-lasting destruction of the countryside by seemingly endless new urban expansions. For this purpose, projects for promoting endogenous development paths aiming at empowering local communities in rural areas and enhancing their environmental, socio-economic and cultural strengths were included. They were intended as integrated multiactor and multi-sector projects focusing on the reconnection of internal areas to the coast, the conservation of the diversity and connectivity of the ecological networks, the improvement of accessibility to rural areas and cultural heritage, the creation of complementary among traditional practices, agriculture multifunctionality and sustainable tourism, as a way to increase opportunities for valorisation of rural areas. Each of the Experimental Integrated Projects developed in different modes and temporalities, involving numerous actors and generating different processes of social interaction and learning. What they have in common is a tentative and exploratory nature, which entails a leaning towards learning all together in a co-productive effort to 'do things' differently from business-as usual. 


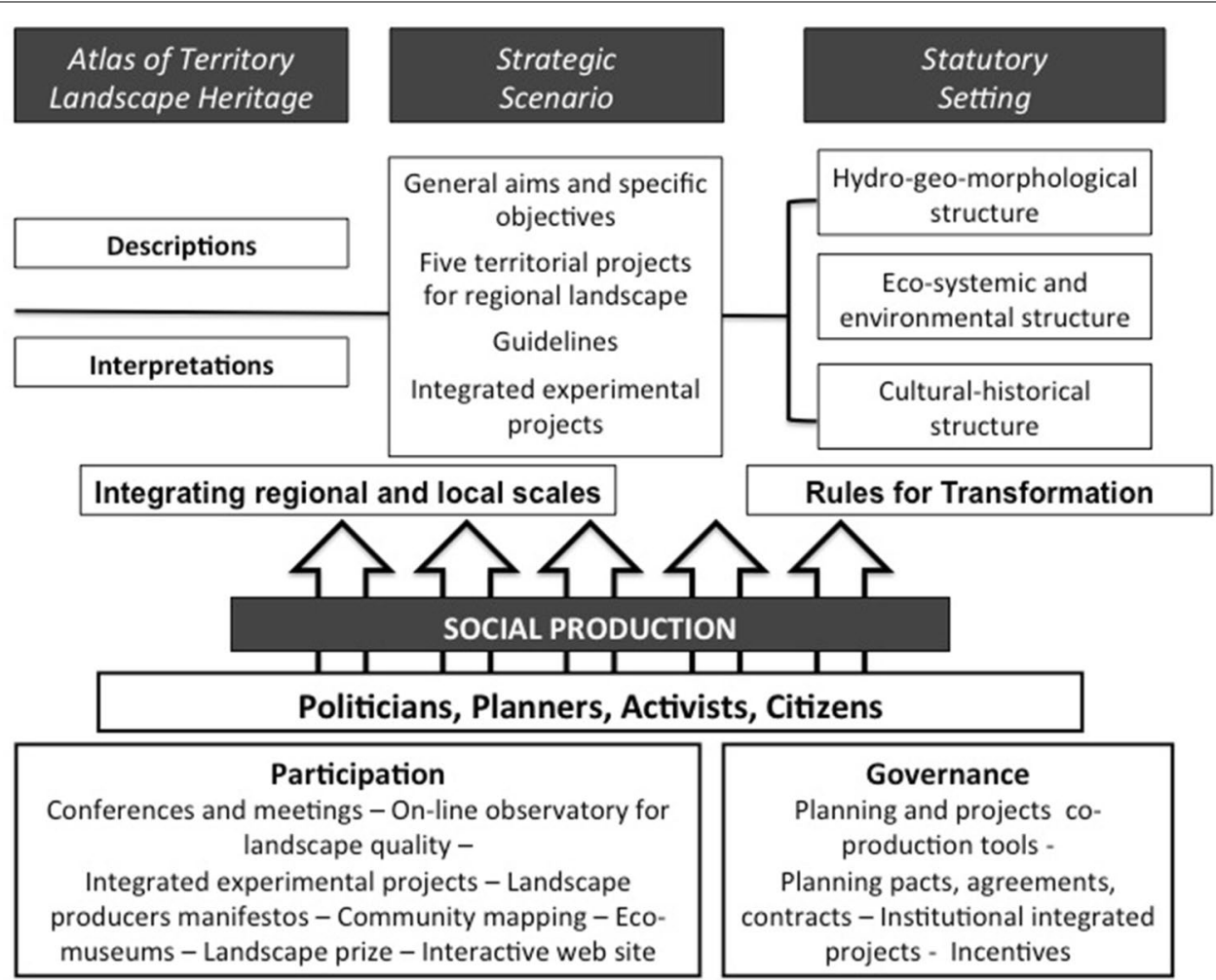

Fig. 1 Overview of the essential parts of TLP

\section{A strategic plan embedded into a statutory setting}

The Social Production of the plan nurtured descriptions and interpretations of the varied regional territorieslandscapes (the Atlas of Territory-Landscape Heritage), and future visions, projects and actions for improving their qualities (the Strategic Scenario) (see Fig. 1). Therefore, the Atlas, the Strategic Scenario and the Social Production were complementary activities that generated concepts, structures, and ideas in radical discontinuity from the business-as usual planning practices.

The construction of the Atlas included descriptions and interpretations of the regional territory-landscape embedding the new narrative concerning both the problems of the past regional development and their potential solutions through the enhancement of regional territorylandscape heritage. This drew on a 'structural' approach which used long-term diachronic analyses (in hydrogeological, ecological, anthropological, and historical terms) to represent co-evolutionary variations in relationships between nature and culture. In such a way, the Atlas identified the multiple identities of places which had been changing over time (Magnaghi 2011).

The Strategic Scenario aimed to outline desirable futures focused on the concept of 'local self-sustainable development'. This pointed out the way in which local communities-individual and social groups-can reconnect the broken relationships between dwellers and producers, and develop their capacity to govern themselves in order to preserve or increase the quality of territorieslandscapes for their environmental and socio-economic well-being.

Desirable futures were not predefined. They should emerge in practice from addressing the Strategic Scenario's objectives, projects and instruments, as well as directives and guidelines. Twelve general aims, ${ }^{5}$ divided into specific objectives, faced the main critical issues of the regional territory. Possible paths towards desirable futures and end results had to be constructed through processes implying the empowerment of actors from civil society in order to give voice to those who have thus

\footnotetext{
${ }^{5}$ They can be summarized as follows. Rebalancing the hydro-geomorphological equilibrium of the river basins, reducing the disparity between abandoned internal areas and over-urbanized coastal areas, improving environmental quality of the degraded landscapes of contemporary urban and coastal settlements, protecting historical rural landscapes and natural resources, improving the aesthetic-perceptive structure of regional landscapes, promoting wide social use of regional landscapes, defining territorial and landscape quality standards for the development of renewable energies, productive activities and infrastructures, and urban and rural housing settlements.
} 
far either been unable to express their views and implement their ideas, or prevented from doing so by the progrowth urban development coalitions.

The Strategic Scenario designed policy instruments specifically aiming to support the promotion of Integrated Landscape Projects to be implemented on the initiative of the regional government or municipalities along with active civil society groups. They were based on the lessons learned from Experimental Integrated Projects and created opportunities to turn such lessons into new decisions and actions.

General aims and specific objectives gave shape to five territorial projects at the regional scale, which require public authorities to adopt a proactive approach. They can be summarised as follows:

- The regional ecological network aiming to improve the overall connectivity of the regional ecosystem;

- The city-countryside pact aiming to improve the quality of life both in rural and urban areas by combining urban and agro-silvo-pastoral policies;

- The infrastructural system for soft mobility aiming to support new ways of enjoying the regional territorylandscape through an intermodal slow mobility network in connection with or as an alternative to the main transport network;

- The integrated protection and improvement of coastal landscapes aiming to assure the general public enjoyment of coastal areas, create synergy with inland areas, stop land take and the formation of a continuous built front along the coast;

- The systems of cultural heritage aiming to overcome the logic of protection of single points of expert interest, and to make tangible and intangible qualities of place known, usable and accessible both to inhabitants and tourists.

The Strategic Scenario had no prescriptive regulatory function. This was a different planning approach to deal with landscape conservation in Italy, where landscape protection is based on a top-down system of rules limited to protected areas 'cut out' from their context. TLP entrusted the task of achieving the goal of conservation of the entire regional territory-landscape to projects, incentives, and actions able to mobilize social, economic and cultural actors who recognize their social value. As such, it included instilling awareness and care of local natural-cultural heritage, and enabling local communities to respect and enhance it. However, the approval of TLP as a statutory plan, implies that municipal land use plans and regional sectoral plans comply with its legal boundaries. In an institutional context overburdened with ineffective, old land use plans, and pressures for deregulation, using an informal strategic plan detached from the statutory planning system, probably would have created problems of effectiveness and legitimacy much more relevant than those highlighted in Nordic countries (Mäntysalo et al. 2015). Moreover, the statutory framework helps prevent landscapes from being further compromised by the usual practices of development planning (Legacy and Leshinsky 2016).

As a statutory plan, the TLP had to follow the formally established steps of the approval procedure. This faced the emergence of entirely new arenas for discourse and key actors participating. The TLP was adopted by the Apulia regional government in August 2013, following formal consent from local governments and state and regional agencies. Then, it was published and submitted to the mandatory opinion of the regional council committee and made available for 'comments' to the general public. In this stage, planning arenas moved from the informal settings and networks, to the formal institutional settings where decisions are taken. Increasingly, the formal arenas of representative democracy came to play a crucial role in the complex interactions through which the delivery of the TLP was achieved. All at once, the interests that usually had access to representation gained voice. At this time, the discussions that had accompanied the whole plan-making process, turned into an intense conflict. The opposition political parties in the regional council asked to withdraw the TLP adoption, claiming that this would have crippled the regional economy, already severely hit by the 2008 crisis. Representatives of business interests, especially in energy, mining and construction, strongly opposed to the plan approval. This dissent led some representatives of the majority parties in the regional council and local governments to distance themselves from the positions of the regional government that had adopted the plan.

Conflict resolution was due both to intentional actions and unintentional matters. It needed negotiation with interests at stake, 17 formal consultations in the regional council committee, and more than 200 informal meetings with local governments and associations around the region. In this stage the varied array of plan supporters had little voice. The TLP's short-term rules were amended after a difficult formal agreement with the Ministry, in order to give economic actors some time (1 year after the approval) to adapt to the new planning instrument. Conflicting interests at stake between the various economic stakeholders (namely energy industry vs. real estate developers, farmers vs. mining industry) made these unable to propose an alternative vision to that of a more widespread and just development and well-being promoted by the TLP. For the majority parties, a crucial 
role was played by the sense of pride for being Apulia, a southern Italian region not used to positive records, to be the TLP the first regional plan approved entirely in line with the ELC and the Code. ${ }^{6}$

After the decision adopting the TLP, participatory procedures to be followed in accordance with the statutory planning rules, gave all public and private actors the opportunity to submit 'comments' on the TLP. The regional government received 2.450 comments. The greater part of them came from landowners, private individuals or companies, to whom the plan took away the possibility to build in valuable, fragile or at risk areas (i.e., sea coasts, rivers, forests and natural pastures, archaeological sites, peri-urban and rural areas). The regional government examined all the comments, whether they had been received within the prescribed deadline or out of time, in order to allow as many people as possible to defend their own interests. It accepted or rejected each comment transparently and within the law, using 'good arguments', i.e. based on the Code rules and TLP aims and objectives. The plan thus amended was approved with the agreement of the Ministry in February 2015.

\section{What could we learn from and about practicing transformative planning?}

The TLP experience was an attempt to practice transformative planning. This experience can be looked upon as an "extreme/deviant case" (Flyvbjerg 2006, p 229). Thus, it cannot be generalized. But precisely because of the neatness of certain assumptions and characteristics of an extreme case, it can shed light on some critical issues concerning transformative planning.

As we have seen, the TLP experience implied changes in values and concepts, discourses and practices, planning approach and instruments. It involved the entire regional territory, and combined statutory and strategic planning, top-down and bottom-up approach. The planmaking process alternated phases that opened up transformative cultural processes with phases of discussion and mediation with forces resisting change, which degenerated into conflicts in the formal decision-taking stage.

\footnotetext{
${ }^{6}$ As such, the plan had exerted a certain influence on the new territory-landscape planning of other Regions and on the guidance for the preparation of the new landscape plans in compliance to the Code issued by the Ministry for Cultural Heritage and Landscape (http://www.pabaac.beniculturali.it/openc $\mathrm{ms} /$ multimedia/BASAE/documents/2012/01/17/69d80134a24aef90d016 99bd8ee6bcb3_circolare3020111.pdf). The Ministry considered the plan a best practice (See press agency http://www.ansa.it/puglia/notizie/2015/01/16/ franceschini-regioni-guardino-a-puglia_41c6fe16-63e3-46f4-adb4-fa53749963 $8 \mathrm{c} . h \mathrm{tml})$. This was certainly unusual for a southern Italian region that is used to negative records both on economy (e.g. GDP, employment) and environmental protection (eg. high rates of illegal buildings, wells, quarries), and is considered unable to produce innovation and change (Banca d'Italia 2010; D’Antonio 1992).
}

The TLP deconstructed the concepts of territory and development at the heart of the post WWII Apulian land use planning practices and spatial change that had destroyed natural and cultural resources. The TL planmaking process started from taking a critical distance from the pressure for 'economic competition' dominating the development discourses across Europe. The critique was connected with a constructive vision. The new concept of 'self-sustainable local development' emphasized the need to halt following north-western development paths (Cassano 2012), and to begin talking about and producing the Apulia territory-landscape from a different local, endogenous perspective. This required to rise social 'place consciousness.' The foundation of TLP on specific values was made explicit: natural and cultural heritage were considered as common goods and, in the light of these values, action principles to bring about a changed reality were stated.

The Social Production process and the concept of 'self-sustainable local development' were experienced in practice, within a process that took extensive time and showed only some immediate results. This highlighted how problematic was turning the concept of 'self-sustainable local development' pursued in academic research, into significant achievements in the real world. But such a concept gave the TLP political support in moving towards, even if not achieving, the desirable structural change. As such, it opened horizons to the future search for further transformations, "keeping the image of that ultimate goal as the second dimension of the one dimensional world to which day-to-day practice is in danger of confining us" (Marcuse 2017, p 46).

The TL planning process fostered a change of (some of) the usual practices of land use transformation in a number of places of Apulia region. This was possible because of the intense interactive process of Social Production of the plan. During this process social practices seeking to build citizens' rights into the territory-landscape were 'discovered' around Apulia, and new social practices were stimulated, and for both of them the conditions favouring joint action between grassroots organisations and regional/local governments were created. This made citizenship rights also an opportunity for greater responsibility for people and organizations towards the future of territory-landscape. Potential actors, such as communitybased action groups and local environmental associations were elicited a commitment to engage in a transformative practice of its own. Some of these groups had fought against development-as-growth practices, most often in a minority and marginalized position. During the TL planning process they had the opportunity to find themselves in an empowered position while others had the possibility to look at the government not as an antagonist but as 
an ally. Together, they tried to change the situation they had criticised. Most of them grasped this unique chance for change.

The Experimental Integrated Projects developed in the TL planning process were crucial to this purpose. As indicated before and argued in Albrechts et al. (2019), politics of empowerment-as mobilizing practices of collective political learning and organization-and politics of place could supplement each other in co-production experiences developed at the regional and local levels.

Acting as a hegemonic force, the regional government inevitably triggered power relations and dynamics of inclusion and exclusion. For how open the TL plan-making process might have been, only some active groups of the Apulian population could make their voices heard at all stages of the process. While some groups had the opportunity to be included in co-production activities, other groups and critical voices were excluded from the process. In effect, including 'dissensual practices' (Rancière 2010) in the Social Production of the plan would have inevitably weakened the TLP plan making process and the Social Production process itself. Yet, as a result, such a selective combination of inclusion and exclusion of dissensus weakened activism as a means of radical opposition to dominant power.

Transformative planning involves decisions that unavoidably implicate ethical judgement, (re)distributive effect, and different costs and benefits for diverse social groups. In contrast with much contemporary spatial planning that "mobilises and reproduces acquiescence for policies and strategies that favour certain groups or interests whilst marginalising more radical alternatives incorporating (and containing) issues such as quality of life, sustainable development and social justice insofar as they did not conflict with the mainstream growth agenda" (Allmendinger and Haughton 2012, p 5), the TLP pursued a selective purpose: the protection of territory-landscape. Thus its strategy deliberately excluded the visions of aggressive economic powers such as building and energy industry.

The collective appropriation of territory-landscape as a common good is always contested. The TLP tried to empower a number of social groups who were likely to be deprived of such a common good, some of which had neither voice nor awareness of being dispossessed. On the other hand, it discontented some established economic powers. Their voice was heard loudly in the approval phase, thanks to the guarantee of inclusiveness, transparency and responsibility provided by the statutory planning system. Although these were unable to twist formal procedures to their advantage, their deregulatory initiatives and economic growth discourses are still powerful.
Planning literature highlights how difficult is to turn single episodes of transformative planning practice into enduring change (Healey 2006). Spatial planning practices unavoidably deal with situations characterized by uncertainty, instability, and value conflict (Schön 1983). Many episodes of transformative practices on a local scale vanish with a change of government. Interests and passions that sustained them may quickly turn into discontent and frustration. This may happen also to the TLP and the Experimental Integrate Projects co-produced during the planning process. Approving the TLP as a statutory plan, which had the formal approval in the representative democracy settings, strengthened the legitimacy to its contents and projects. But this is not enough to make these spread far into the 'mainstream' governance processes.

Regulatory statutory spatial planning lacks in visioning and is not able to mobilize local actors around an idea of change and to intercept the new visions of local actors who are mobilizing and acting for change. However, in the TLP experience it was necessary in order to establish the rules governing physical transformation. They aimed at preventing the destruction of natural and cultural resources, avoiding developments that are harmful to the environment and landscape, and curbing the privatization of common goods. After the approval, the TLP gave voice to old and new groups of activists and critical perspectives that had been weakened by the inclusion of 'dissensual practices' (Rancière 2010) into the social production of the plan. They appealed to the plan to counteract development options that conflict with their values. ${ }^{7}$ And in future they may also contest the plan for not being able to effectively protect the regional environment.

On the other hand, the strategic approach was essential for not considering the plan's intentions, visions and rules just as aiming to protect territory-landscape from development. Intentions, visions and rules were consistent with a new narrative that a part of the economic, social, cultural, and political groups shared as a support for a form of development that considers territory-landscape as a common good to be protected and enhanced for a more just development and well-being. The strategic enabling function of TLP motivated actors usually marginalised by the pro-growth urban development model, with hopes for widespread transformative planning practices.

\footnotetext{
${ }^{7}$ Some examples can be useful for understanding how the plan offers antagonist groups anchorages to prevent pro-growth development.

http://www.salviamoilpaesaggio.it/blog/2014/05/puglia-a-bisceglie-la-nuova -area-industriale-si-chiama-paesaggio-eco-produttivo/.

http://www.salviamoilpaesaggio.it/blog/2014/05/puglia-no-allinutile -e-devastante-progetto-della-nuova-strada-dei-colli/.

http://www.leccenews24.it/attualita/tap-niente-deroghe-dalla-regione-pugli a.htm.

http://www.brindisioggi.it/parco-eolico-tuturano-legambiente-rispettare -piano-paesaggistico-regionale/.
} 
However, if the new narrative had failed to be reflected in practices and remained completely detached from these, it would have betrayed actors' expectations and hopes for change. Experimental Integrated Projects were essential to show 'live', during the plan-making process, the ways in which the TL plan could have been implemented. They enabled transformative processes already under way to develop and strengthen, and (possibly) 'travel' and give rise to other projects and actions. The ability to do things was essential to demonstrate that some form of radical change was possible.

Planning for structural change should be seen as a social learning process that requires continuous critical reflection on the part of planners and relevant publics (Friedmann 2005, p 214). Experimental Integrated Projects opened the possibility of a widening of participants' cultural and operational horizons, and constituted an opportunity for mutual learning. They were far from proposing 'ready to use' solutions to complex problems. They demonstrated both to the regional government team and local actors how difficult may be to move from discourses to practices and, conversely, how practices can contribute to making discourses richer in content and detail. Involving many people in practical activities throughout the region was also crucial to keep social tension alive during the long time needed to achieve the approval of the TLP.

The aim of sustaining on-going experiences and promoting new ones contributed to bring the milieu to the fore, or rather the foundation of a fluid and dynamic regional collective identity anchored to the territorylandscape values. An open and future-oriented idea of protection and enhancement of local cultural and environmental resources linked to the concept of 'self-sustainable local development', revealed the potential of social innovation based on culture and identity building (Moulaert et al. 2005) to break self-reinforcing processes and initiating a process of change.

The trajectory of planning episode usually combines both 'path dependency' and generative force, shifting discourses and practices, and reshaping policy communities and institutional arenas (Healey 2007).

The strategic approach was the product of a specific institutional setting which shaped what was imagined as strategic, and yet which may come to have the capacity to challenge and transform that setting (Hajer 2005). In this respect, the ability to do things is crucial for any public policy that really wants to achieve the political goals it has set. It is even more important for transformative planning, since it has to demonstrate that doing things differently is possible. After the TLP's approval, projects and actions inspired by the concept of self-sustainable local development and supported by the Strategic Scenario were developed around Apulia on the initiative of local associations and municipalities, ${ }^{8}$ or the regional government. ${ }^{9}$ This highlights the openness of the TL planning process, and the ability of the plan to solicit a proactive role of government institutions and local groups. On the other hand, conformation or coordination of land use plans to the TLP, which was required by the Code not later than 2 years after the TPL approval, and involved the powers of the Region and Ministry, is in critical delay. The zoning and rules governing physical transformation, which catalyse economic interests in future options for urban growth, are acting as neutralising or counteracting forces that hinder the development of grassroots transformative practices and local changes, and push back to the old business-as-usual planning practices.

\section{Epilogue}

The institutionalization of the new TLP's narrative (Healey 2006), i.e. its penetration in the norms, attitudes and practices in the most sensitive social groups, thus providing a basis for structural change, requires great effort and much time (Albrechts and Balducci 2013). The long process of Social Production of the plan was essential to create a common base of storytelling, language, and awareness through interaction. It required a proactive role of the public sector, as a promoter or supporter of new projects and actions. Thus, if the Social Production of territory-landscape is interrupted in the implementation phase and the old bureaucratic, restrictive-regulatory planning tradition in landscape protection from development takes over, this process will stop and the basis for structural change will be gradually destroyed. If the public sector will be inactive rather than proactive in promoting project and actions for self-sustainable local development, the dynamics of private sector will define the development agenda, and the public sector will only have to play a reactive role.

For this purpose, it is crucial that politics is willing to take risks of promoting a radical change. This requires the ability to demonstrate, through robust arguments and concrete examples, the social, environmental and economic damage caused by the dominant development

\footnotetext{
${ }^{8}$ For example the eco-museum of the sail swamp in Taranto promoted by a group of associations in 2016 and funded by the Foundation with the South (http://www.esperienzeconilsud.it/ecopamar/) and the implementation of city-countryside pact in the municipality of San Severo in the Province of Foggia (http://mosaicodisansevero.org).

9 See the call for proposals approved in February 2018 for financing projects within the framework of the "regional ecologic network", "city-countryside pact" and "integrated protection and improvement of coastal landscapes". http://www.regione.puglia.it/documents/10192/21433302/DET2531120 18.pdf/b79238bf-e558-4b6e-bd4c-afed589eb4ce?version=1.0.
} 
model in everyday living places. At the same time, it requires the capability of being constantly open. Open to new imaginary and joining the unthinkable to the experience, that is, giving concreteness to this imaginary by means of a series of present actions. These show that what seemed to be impossible would be possible.

\section{All this forms the core of transformative practices.}

\section{Acknowledgements}

Not applicable.

\section{Authors' contributions}

The authors contributed equally to this work. All authors read and approved the final manuscript.

\section{Funding}

This research did not receive any specific grant from funding agencies in the public, commercial, or not-for-profit sectors.

\section{Availability of data and materials}

The data and materials used and analyzed in the study are available from the corresponding author on request or are available online at the websites listed in the paper.

\section{Competing interests}

The authors declare that they have no competing interests.

\section{Author details}

${ }^{1}$ KU Leuven, Leuven, Belgium. ${ }^{2}$ Politecnico di Bari, Bari, Italy.

Received: 14 Auqust 2019 Accepted: 23 December 2019

Published online: 14 January 2020

\section{References}

Ackoff R (1981) Creating the corporate future. John Wiley, New York

Agnew J (2011) Landscape and national identity in Europe: England versus Italy in the role of landscape in identity formation. In: Roca Z, Claval P, Agnew J (eds) Landscapes, identities, development. Ashgate, Farnham, pp $37-50$

Albrechts L (2010) More of the same is not enough! How could strategic spatial planning be instrumental in dealing with the challenges ahead? Environ Plan B 37:1115-1127. https://doi.org/10.1068/b36068

Albrechts L (2013) Reframing strategic spatial planning by using a coproduction perspective. Plan Theory 12(1):46-63. https://doi.org/10.1177/14730 95212452722

Albrechts L (2015) Ingredients for a more radical strategic spatial planning Environ Plan B 42(3):510-525. https://doi.org/10.1068/b130104p

Albrechts L, Balducci A (2013) Practicing strategic planning: in search of critical features to explain the strategic character of plans. Plan Rev. 49(3):16-27. https://doi.org/10.1080/02513625.2013.859001

Albrechts L, Barbanente A, Monno V (2019) From stage-managed planning towards a more imaginative and inclusive strategic spatial planning. Environ Plan C. https://doi.org/10.1177/2399654419825655

Allmendinger P, Haughton G (2012) Post-political spatial planning in England: a crisis of consensus? Trans Inst Brit Geogr 37(1):89-103. https://doi.org/1 0.1111/j.1475-5661.2011.00468.x

Banca d'Italia (2010) II Mezzogiorno e la politica economica dell'Italia [The Mezzogiorno and the economic policy of Italy]. Banca d'Italia, Roma

Cassano F (2004) Homo civicus. La ragionevole follia dei beni comuni [Homo civicus. The reasonable madness of common goods]. Dedalo, Bari

Cassano F (2012) Southern Thought and Other Essays on the Mediterranean. Fordham University, Bronx, NY (Or. Ed. 1996)

CEC-European Commission (1997) The EU Compendium of Spatial Planning Systems and Policies, Regional Development Studies 28. Office for Official Publications of the European Communities, Luxembourg
Chia R (1999) A "Rhizomic" model of organizational change and transformation: perspective from a metaphysics of change. Br J Manag 10:209-227. https://doi.org/10.1111/1467-8551.00128

Cosgrove DE (1984) Social formation and symbolic landscape. Croom Helm, London

Council of Europe (2000) European Landscape Convention. CETS No. 176. Council of Europe, Strasbourg. https://www.coe.int/en/web/landscape. Accessed 12 July 2019

D'Antonio M (1992) II Mezzogiorno. Sviluppo o stagnazione? [The Mezzogiorno. Development or stagnation?]. il Mulino, Bologna

Damiani M (2011) Nichi Vendola: for the New'Laboratory' of the Italian Left. Bull Ital Politics 3(2):371-390

De Bono E (1992) Serious creativity. Using the power of lateral thinking to create new ideas. Harper Business, New York

Duran M (2015) Mediterranean paradiplomacies: the dynamics of diplomatic reterritorialisation. Koninklijke Brill, Leiden NL

Etzioni A (1971) The active society: a theory of societal and political processes. Collier Mac Millan, London

Fabbro S (2003) The new regional territorial plans in Italy: approaches, visions, effectiveness. Urbanistica 121:57-86

Flyvbjerg B (2006) Five misunderstandings about case-study research. Qual Inquiry 12(2):219-245. https://doi.org/10.1177/1077800405284363

Friedmann J (1982) The good society. MIT Press, Cambridge

Friedmann J (1987) Planning in the public domain: from knowledge to action. Princeton University Press, Princeton

Friedmann J (2005) Globalization and the emerging culture of planning. Progr Plan 64:183-234. https://doi.org/10.1016/.jprogress.2005.05.001

Gates B (2008) How to fix capitalism? Times 11 August, 24-29

Gelli F (2006) Prove di governo regionale: il caso della Puglia. Appunti per una "società pensante" [Tests for regional government: the case of Apulia. Notes for a "thinking society"]. In G. Gangemi (ed), Le elezioni come processo [Elections as a process]. FrancoAngeli, Milano, pp 155-198

Hajer M (2005) Setting the stage: a dramaturgy of policy deliberation. Admin Soc 36(6):624-647. https://doi.org/10.1177/0095399704270586

Hames R (2007) The five literacies of global leadership. Jossey-Bass, San Francisco

Hamilton C (2004) Growth Fetish. Pluto Press, London

Healey P (2006) Transforming governance: challenges of institutional adaptation and a new politics of space. Eur Plan Stud 14(3):299-320. https://doi. org/10.1080/09654310500420792

Healey P (2007) Urban complexity and spatial strategies: towards a relational planning for our times. Routledge, London

Heynen N, Kaika M, Swyngedouw E (2005) Urban political ecology: politicizing the production of urban natures. In: Heynen N, Kaika M, Swyngedouw $E$ (eds) In the nature of cities: urban political ecology and the politics of urban metabolism. Routledge, London, pp 609-619

Krumholz N, Forester J (1990) Making equity planning work. Temple University Press, Philadelphia

Landry C (2000) The creative city: a toolkit for urban innovators. Earthscan, London

Legacy C, Leshinsky R (2016) Instruments of Planning. Tensions and challenges for more equitable and sustainable cities, Routledge

Magnaghi A (2005) The Urban Village: A Charter for Democracy and Self-sustainable Development. Zed Books, London and New York (Or. Ed. 2000)

Magnaghi A (2011) The Apulia approach to landscape planning. Urbanistica 147:8-13

Mäntysalo R, Jarenko K, Nilsson KL, Saglie IL (2015) Legitimacy of Informal Strategic Urban Planning - Observations from Finland, Sweden and Norway. Eur Plan Stud 23(2):349-366. https://doi.org/10.1080/09654 313.2013 .861808

March L (2011) Radical left parties in contemporary Europe. Routledge, Basingstoke

Marcuse P (2017) From Utopian and Realistic to Transformative Planning. In: Haselsberger B (ed) Encounters in Planning Thought: 16 Autobiographical Essays from Key Thinkers in Spatial Planning. Routledge, New York, pp $35-50$

Metzger J (2013) Placing the stakes: the enactment of territorial stakeholders in planning processes. Environ Plan A 45(4):781-796. https://doi. org/10.1068/a45116 
Meyerson M, Banfield E (1967) Politics, planning and the public interest. The case of public housing in Chicago. Collier-MacMillan, London

Mishan E (1967) The costs of economic growth. Staple Press, London

Moulaert F, Martinelli F, Swyngedouw E, Gonza'lez S (2005) Towards alternative model(s) of local innovation. Urban Stud 42(11):1969-1990. https://doi. org/10.1080/00420980500279893

Nogué J, Wilbrand SM (2017) Landscape identities in Catalonia. Landscape Res 43(3):443-454. https://doi.org/10.1080/01426397.2017.1305344

Ozbekhan H (1969) Towards a general theory of planning. In: Jantsch E (ed) Perspectives of planning. OECD, Paris, pp 45-155

Pedroli B, Antrop M, Pinto Correira T (2013) Living landscape: the European landscape convention in research perspective. Landscape Res 38(6):691694. https://doi.org/10.1080/01426397.2013.873269

Pelling M, Manuel-Navarrete D, Redclift M (eds) (2011) Climate change and the crisis of capitalism. A chance to reclaim, self, society and nature. Routledge, London

Purcell M (2009) Resisting neoliberalization: communicative planning or counter-hegemonic movements? Plan Theory 8(2):140-165. https://doi. org/10.1177/1473095209102232

Rancière J (2010) Dissensus: On Politics and Aesthetics. Continuum, London

Romano O (2005) Virtù primarie. Note sul laboratorio politico pugliese [Primary virtues. Notes on the Apulian political laboratory]. Democrazia e Diritto 1:217-237

Sachs W, Esteva G (2003) Des ruines du développement. Le Serpent à Plumes, Paris
Sager T (2016) Activist planning: a response to the woes of neo-liberalism? Eur Plan Stud 24(7):1262-1280. https://doi.org/10.1080/09654313.2016.11687 84

Sandercock L (1998) Towards cosmopolis: planning for multicultural cities. Wiley, Chichester

Sandercock L (2003) Out of the Closet: the importance of stories and storytelling in planning practice. Plan Theory Pract 4(1):11-28. https://doi. org/10.1080/1464935032000057209

Schön DA (1971) Beyond the stable state. Norton \& Co, New York

Schön DA (1983) The reflective practitioner: how professionals think in action. Basic Books, New York

Settis S (2013) II paesaggio come bene comune [Landscape as a common good]. La Scuola di Pitagora Editrice, Napoli

Throgmorton J (2003) Planning as Persuasive Storytelling in a Global-Scale Web of Relationships. Plan Theory 2(2):125-151. https://doi.org/10.17077 /h5mm-k1r6

Yanow D (2000) Conducting interpretive policy analysis. Sage, Newbury Park

\section{Publisher's Note}

Springer Nature remains neutral with regard to jurisdictional claims in published maps and institutional affiliations.

\section{Submit your manuscript to a SpringerOpen ${ }^{\odot}$ journal and benefit from:}

- Convenient online submission

- Rigorous peer review

- Open access: articles freely available online

- High visibility within the field

- Retaining the copyright to your article

Submit your next manuscript at $\boldsymbol{\nabla}$ springeropen.com 